\title{
A CASE OF INTUSSUSCEPTION
}

OF THB

\section{UPPER END OF THE RECTUM DUE TO OBSTRUCTION BY A NEW GROWTH.}

\begin{abstract}
EXCISION OF THE INTUSSUSCEPTION; SUTURE OF THE REMAINING BOWEL; COMPLETE RECOVERY.
\end{abstract}

BY

ARTHUR E. BARKER, F.R.C.S.,

SURGEON TO UNIVERSITY COLLEGE HOSPITAL; TEACHER OF PRACTICAL SURGERY AT UNIVERSITY COLLEGE.

Received December 14th, 1886-Read May 10th, 1887.

The interest in every form of intestinal obstruction appears to increase with the improvements in our methods of dealing with them. And though the condition met with in the following case is one of great rarity, and not likely often in a lifetime to come under the notice of any one man, the case would be nevertheless of much interest if it only offered one more illustration of what may be undertaken and achieved with the help of strict antiseptic precautions. I believe that without the latter this operation would not have been justifiable or successful ; with them it was one which, albeit difficult, offered no complications, and was followed by a rapid and perfect recovery. 
L. E. S-, æt. 28, was admitted into University College Hospital on June 7th, 1886, complaining of great constipation and the discharge from the rectum of much offensive purulent matter and clots of blood. All her life she has been subject to constipation, and more so since her marriage five years ago. She has been in the habit of allowing her bowels to be confined for two or three days, or even as long as a week. Otherwise she has been a healthy woman, and is so now to all appearance. Her third and last confinement was four months ago. The labour was difficult and painful, and forceps were necessary. Her family history is good, except that her father died of phthisis.

The trouble in the rectum commenced sixteen months ago with the appearance of small streaks of blood. Eight or ten months ago she became conscious of some foreign body in the bowel which began to prolapse about two or three months later at each stool. At this time blood was very forcibly expelled each time just before the prolapse, which had to be returned before the fæces could be passed.

She was treated with astringent injections at this time, with some benefit, but her medical man discontinued this treatment on account of her pregnancy. There has never been any diarrhœa alternating with constipation. The motions consist of hard lumps varying in size from that of a bantam egg to a marble, more commonly the first. A large, soft, irregular mass can be felt by the finger in the rectum. Under an anæsthetic it was drawn down and made to project from the anus, and being carefully examined was found to consist of an intussusception with a mass of new growth at its apex. This mass nearly surrounded the bowel with nodular projections, and occupied about two inches of its length. The mucous membrane for a short space on the right side of the bowel was not invaded. The infolding of the mucous membrane was felt about three inches from the anus, so that the position of the growth, with the intussusception reduced, 
would be about six or seven inches from the anus. The mass could be sufficiently drawn through the anus to expose about an inch of healthy bowel above the edge of the growth. No swelling could be detected in the left iliac fossa, and no infiltration of the intestinal wall beyond the immediate seat of the growth.

Through the kindness of my colleague, Mr. Christopher Heath, this patient was placed under my care, and I remored the whole of the intussuscepted portion of intestine, including the growth.

Operation June 9th: Ether. The patient was laid upon the left side with the thigh well flexed. The rectum was then thoroughly washed out, a quantity of fæculent and purulent matter coming away. Then the intussusception was pulled well out of the anus and washed, within and without, with 5 per cent. carbolic acid solution, which was also made to flush the space between the intussusceptum and intussuscipiens, until the whole area of operation was thoroughly cleansed. Holding the two layers of the intussusceptum well together between the left index finger in the bowel, and the thumb on the latter beyond the growth, I passed a needle on a handle, threaded near the eye, with silk, through its double wall from without towards the lumen. This instrument, however, did not answer, and straight round sewing needles were substituted for it through the rest of the operation. With these a row of stitches was made to encircle the bowel, uniting the two layers of the intussusceptum firmly to one another, well above the new growth. Each thread was passed from the surface into the lumen and then back, and included from one sixth to one quarter of an inch of the circumference of the bowel in its loop. The intervals between the stitches were guarded by a second row similarly introduced about half an inch higher up the bowel. The growth was then cut away with scissors close below the lowest ring of stitches; but before the section was completed a few stitches were introduced above a spot at which the first row appeared to run too vol. LXX. 
close to the growth, and the section was carried at this spot above the first row. After this section had been completed, and the mass of the intussusceptum-removed as a continuous ring, only one small vessel bled. This was tied with silk. The whole cut surface was then dried, and the bowel was returned, a pad of iodoform wool being placed over the rectum.

The mass removed consisted of the growth and about two thirds of an inch of healthy bowel above it. The peritoneal covering was quite healthy, and the growth well limited by the operation. The lobules of the neoplasm presented all the appearances of an adenoid tumour on the surface. There was not, to the naked eye, any infiltration of the wall of the bowel underneath. Each lobule was more or less pedunculated, and on microscopic section showed a fibrous centre with strands radiating in all directions, forming fine papillæ about half an inch long. Each of the latter was formed of delicate connective tissue covered with columnar epithelial cells. In the central pedicle normal tubular glands were seen cut at different angles to their axes. At the base of the growth there was a suspicious irregularity in the arrangement of the cells, islands of which were seen separated from one another by strands of connective tissue of varying thickness; but whether the neoplasm was actually malignant or only adenomatous it is difficult to say from microscopic examination.

There was considerable shock after operation, but this soon yielded to the usual remedies, but no brandy was given. The patient was sick soon after her return to bed, and during the night, but not subsequently. The next morning (10th) the pulse was good, 116, temp. $1000^{\circ}$ There was no distension of the abdomen, and only a feeling of being somewhat "bruised" in the left iliac region. She was put on spoon diet with ice to suck. Flatus was passed in the evening.

11th.-Patient better, no abdominal tenderness or any kind of pain. Takes beef-tea. The pad of wool over the. 
anus was changed; there was very little discharge' on it.

12th.-Patient is quite free from any pain; pulse 104. temp. $101 \cdot 2^{\circ}$.

13th.-The temperature fell to normal to-day, and remained below $100^{\circ}$ from this up to the end of convalescence.

14th.-To-day the threads which hung out of the anus were cut short. A large, well-formed motion, without any scybala, was passed, and with no sign of pus or blood; one ligature came away with it. Altogether three motions were passed on this day, the first causing some pain.

17th.-Quite comfortable, and longing for solid food. A large stool, partly solid and partly liquid, was passed for the first time since the 14th.

On the 21st she required Conf. Sennæ, and an enema, and had three motions as a consequence. None of the threads ever appeared since the first. Fish was allowed to-day.

On the 25th a saline aperient was ordered, as there had been a great accumulation of fæces in the colon before the operation, and all had not come away yet. This draught and an enema produced a free evacuation.

On the 29th I made a digital examination of the rectum, and could feel the ridge produced by stitching the cut edges together. There was no trace of stricture.: The threads were not felt.

A few days later the patient left for her home, feeling and looking perfectly well. I have since heard that she remains so.

Remarks.-Intussusception of the rectum appears from' published statistics to be one of the rarest forms of intestinal invagination. The relative frequency of the various forms is thus given by Lichtenstein, quoted by Treves. Out of 100 cases, 44 were ileo-cæcal, 30 enteric, 18 colic (including rectal), and 8 ileo-colic. If one comes to look 
into the matter more closely, it is found that the number of actual rectal intussusceptions among the 18 per cent. set down under the heading colic is very small.

It is also extremely rare to find intussusception of any kind caused by malignant growths in the wall of any part of the bowel. Polypi are a common cause of the condition, but non-pedunculated new growths very rarely so. I have been surprised at the small number it is possible to collect from home and foreign sources. Mr. Treves, in his work on 'Intestinal Obstruction,' only speaks of having seen two. One of these, treated by my colleague Prof. Heath, is in our museum at University College, the other in the museum of the Royal College of Surgeons. After some trouble in searching English and Continental literature, I am only able to collect eight authentic cases in addition to the two just referred to, and the case which is the subject of this paper, making eleven in all. Lichtenstein mentions four, but rejects one of them (Cruveilhier's). Another of his references (Quain's case) I have been unable to verify after search through the whole of the 'Transactions of the Pathological Society,' in which he states it is to be found. Of the remaining two, one was seen by himself, the other by Knauss. Then there is a case of adenoid new growth of the sigmoid flexure with intussusception recorded by Mr. Durham in 'Path. Trans.,' vol. xxiii, p. 116, and another of adenoid cancer of the cæcum with intussusception by Dr. Greenhow, Ibid., vol. xviii, p. 114.

The fact that these last two are the only cases of the kind to be found throughout the whole series of the 'Path. Trans.,' further attests the rarity of the conjunction of non-polypoid growths with intussusception. The next case I find recorded by Fleiner, in Virchow's 'Archiv.' The mass was excised by abdominal section by Czerny, of Heidelberg, and turned out to be an intussusception due to an "adenoid carcinoma" of the cæcum. Then two cases are recorded in the 'Progres Médical,' No. 8, 1886, by Verneuil, in which the patients, old women, suffered 
from intussusception of the rectum due to adenoid epithelioma. Quite recently Kulenkampff has described a similar case in the 'Centralblatt für Chirurgie,' 1886, No. 47, and my own case makes the eleventh. In six of these the sigmoid flexure, or upper part of the rectum, was the seat of the disease, in the other cases the latter was found in or near the cæcum.

Of the six rectal intussusceptions, four were removed through the anus, the two remaining being left untouched. Verneuil appears to have been the first to attempt this. In his first case it was accomplished with the écraseur, but the peritoneal cavity was opened in the operation, and the patient died in a couple of days. In his second case he first performed linear rectotomy to reach the mass, then placed Dupuytren's enterotome above the growth to provoke adhesion, and, at the end of a few days, further secured the walls of the bowel with six sutures before cutting away the intussusception. The patient died two days later of peritonitis, the result of fæcal extravasation, in spite of the stitches. Kulenkampff drew down the tumour in his case, and cut it away, stitching apparently as he went. At the last cut he was aware that he had wounded a knuckle of bowel adherent to the peritoneal surface of the rectum. This, however, he sutured at once through the wound in the rectum. When the latter had been stitched, the stump was only replaced within the anus. The patient recovered from the operation, but with complete obstruction of the bowels, so that on the tenth day the colon was opened in the left groin, and an artificial anus was formed. Later, the rectum became pervious, and the artificial opening appears to have closed, the patient making a good recovery. In my own operation the large number of stitches used at short intervals prevented any gaping of the peritoneal wound, and thus saved the peritoneum from the contamination which took place in Verneuil's second case. I suppose that in all cases operated on in this way there will be always a risk of opening an adherent loop of small intestine, but by careful 
342 INTUSSUSCEPTION OF THE UPPER END OF THE RECTUM.

palpation the presence of such a loop may be made out, and if a doubt still exists the rectum might be carefully incised above the intussusception before being encircled by stitches.

Note.-Writing in July, 1887, this patient's medical man assures me that she remained perfectly well in every way and had given birth to a healthy child just a year after operation.

(For report of the discussion on this paper, see 'Proceedings of the Royal Medical and Chirurgical Society,' New Series, vol. ii, p. 257.) 